\title{
Дифференциально-
}

\section{диагностическое значение}

\section{определения прокальцитонина в цереброспинальной жидкости при менингитах у детей}

\author{
Мазанкова Л.Н.' • Гусева Г.Д., ${ }^{1,2}$ Моисеенкова Д.А. ${ }^{1,3}$ • Молотилова Т.Н. ${ }^{3}$ • Алешина Н.И.
}

Мазанкова Людмила Николаевна д-р мед. наук, профессор, заведующая кафедрой детских инфекционных болезней

$\triangle 125993$, г. Москва, ул. Баррикадная, 2/1, Российская Федерация.

Тел.: +7 (903) 6289242.

E-mail: mazankova@list.ru

Гусева Галина Дмитриевна - канд. мед. наук, ассистент кафедры детских инфекционных болезней', врачинфекционист отдела инфекционного контроля

Моисеенкова Дарья Андреевна аспирант кафедры детских инфекционных болезней', врач-педиатр детского боксированного отделения ${ }^{3}$

Молотилова Татьяна Николаевна заведующая экспресс-лабораторией

Алешина Нина Игоревна - врачлаборант экспресс-лаборатории ${ }^{3}$
Актуальность. В патогенезе системных воспалительных процессов при генерализованных бактериальных инфекциях важное значение имеет активация образования провоспалительных цитокинов, сопровождающаяся синтезом прокальцитонина и повышением его уровня в крови. Цель - оценить информативность определения уровня прокальцитонина как биомаркера бактериального воспаления в цереброспинальной жидкости при дифференциальной диагностике менингита бактериальной и вирусной этиологии. Материал и методы. У 88 детей в возрасте от 3 месяцев до 14 лет, госпитализированных в стационар, определяли уровень прокальцитонина в крови и цереброспинальной жидкости методом иммуноферментного анализа. у 45,4\% из них был диагностирован острый бактериальный менингит, у 27,3\% - вирусный менингит и у 27,3\% - синдром менингизма (группа контроля). Результаты. Установлен высокий уровень прокальцитонина в цереброспинальной жидкости у пациентов с бактериальным гнойным менингитом - 0,14 $(0,0 ; 0,34)$ нг/мл ( $<<0,006)$ при норме (группа контроля) 0,07 (0,0; 0,07) нг/мл, коррелирующий с повышением прокальцитонина в крови - 9,8 $(2,05 ; 13,19)$ нг/мл и тяжестью менингита. При вирусных менингитах уровень прокальцитонина определялся ниже контрольных значений - 0,02 $(0,01 ; 0,07)$ нг/мл. Заключение. Определение уровня прокальцитонина в крови и цереброспинальной жидкости может быть рекомендовано к включению в алгоритм дифференциальной диагностики менингита разной этиологии у детей.

Ключевые слова: дети, менингит, прокальцитонин, кровь, цереброспинальная жидкость, алгоритм, дифференциальный диагноз

doi: 10.18786/2072-0505-2015-42-96-102

1 ГБОУ ДПО «Российская медицинская академия последипломного образования» Минздрава России; 125993, г. Москва, ул. Баррикадная, 2/1, Российская Федерация

2 ФГБУ «Федеральный научно-клинический центр детской гематологии, онкологии и иммунологии имени Дмитрия Рогачева» Минздрава России; 117997, г. Москва, ГСП-7, ул. Саморы Машела, 1, Российская Федерация

${ }^{3}$ ГБУЗ города Москвы «Инфекционная клиническая больница № 2 Департамента здравоохранения города Москвы»; 105275, г. Москва, 8-я ул. Соколиной горы, 15, Российская Федерация 
$\prod$

роблема изучения менингита у детей не утрачивает своей актуальности в связи с полиэтиологичностью заболевания и трудностями клинико-лабораторной дифференциальной диагностики бактериальных и вирусных нейроинфекций в острой фазе. Своевременную диагностику бактериального гнойного менингита затрудняет также развитие неспецифических изменений в цереброспинальной жидкости, что приводит к ошибкам в тактике ведения и неблагоприятным исходам.

Несмотря на внедрение в практику современных методов лабораторной диагностики, этиологическая расшифровка этого инфекционно-воспалительного заболевания нервной системы не превышает $60 \%$. В структуре менингита у детей преобладают энтеровирусные - серозные - менингиты, удельный вес бактериальных гнойных менингитов достигает 6\% [1]. В острый период развития бактериальных и вирусных менингитов общемозговой, общетоксический и менингеальный синдромы имеют схожую картину, что не позволяет их дифференцировать клинически. При этом изменения в цереброспинальной жидкости в первые часы от начала заболевания могут иметь разнонаправленный характер, что также ограничивает их дифференциальный потенциал. В связи с этим важным представляется поиск новых альтернативных методов ликвородиагностики с определением дифференциально-диагностических маркеров воспалительного процесса.

Для совершенствования алгоритма диагностики менингита разной этиологии проводились единичные исследования по изучению роли белков острой фазы воспаления: лактата, С-реактивного белка, лактатдегидрогеназы, ферритина, альфа-1-антитрипсина, альфа-2-макроглобулина, гаптоглобина, концентрация которых в острой стадии заболевания значительно изменяется в сторону как увеличения (положительные (позитивные) острофазные реактанты, например, С-реактивный белок), так и снижения (отрицательные (негативные) острофазные реактанты, например, альбумин и трансферрин) $[2,3]$. Известно, что в острый период нейроинфекций вследствие увеличения проницаемости гематоэнцефалического барьера в цереброспинальной жидкости возрастает концентрация ряда белков, таких как нейроспецифическая енолаза (NSE), нейрональный цитоплазматический фермент гликолиза, глиофибриллярный кислый протеин, группа белков S 100, a2GP и др. [4]. В работе Е.М. Мазаевой установлено, что для дифференциальной диагностики вирусных и бактериальных менингитов целесообразно использовать определение концентрации гаптоглобина в цереброспинальной жидкости в острый период заболевания при проведении первой люмбальной пункции [5]. Однако исследование данных маркеров носит сугубо научный характер и нацелено на углубленное изучение патогенетических механизмов развития менингита. Кроме того, определение этих маркеров требует больших затрат и использования зарубежных технологий, что ограничивает применение диагностического метода на практике. Таким образом, продолжается поиск диагностически значимых лабораторных маркеров активности воспалительного процесса в центральной нервной системе, наиболее объективно отражающих особенности развития той или иной нозологической формы.

В последнее время интерес ученых привлекает изучение маркеров острого системного воспаления при бактериальных инфекциях, сопровождающихся бактериемией. Обсуждается диагностическое значение прокальцитонина как биомаркера системной воспалительной реакции, потенциально связанной с активацией в мононуклеарных клетках периферической крови бактериальных липополисахаридов [6, $7,8]$ и провоспалительных цитокинов (интерлейкинов (ИЛ) $1 \beta$ и $1 \alpha$, фактора некроза опухоли альфа (ФНО- $)$ ), стимулирующих синтез матричной рибонуклеиновой кислоты (мРНК), кодирующей образование прокальцитонина. Прокальцитонин относится к маркерам, имеющим довольно высокую специфичность в отношении бактериальных инфекций. Этот белок синтезируется в С-клетках щитовидной железы и является предшественником гормона кальцитонина. При тяжелой инфекции (бактериальной, грибковой, паразитарной) с манифестацией воспалительного процесса под влиянием эндотоксинов, бактериальных тел при участии цитокинов происходит резкая экстратиреоидальная выработка прокальцитонина, причем без повышения уровня конечного гормона кальцитонина. Самые высокие концентрации прокальцитонина определяются при бактериальном сепсисе и септическом шоке. Установлена способность прокальцитонина избирательно повышаться при тяжелых бактериальных, грибковых и паразитарных, но не при вирусных, ограниченных бактериальных инфекциях, неоплазиях и аутоиммунных расстройствах, а также высокая корреляция с выраженностью воспалительной реакции, что вызывает интерес 
исследователей к возможности клинического применения прокальцитонина как маркера тяжелой инфекции. Выявлено, что провоспалительные цитокины (ИЛ-1 $\beta$, ИЛ-2, ИЛ-6, ФНО- $\alpha$ ) стимулируют экспрессию мРНК прокальцитонина и вызывают увеличение внутриклеточного содержания компонентов прокальцитонина. Синтез этого маркера выявлен также в макрофагах, гранулоцитах, В- и Т-лимфоцитах [9], что определяет патогенетическую связь воспалительного процесса с особенностями иммунного ответа при проникновении патогенов в центральную нервную систему. Оценка содержания различных медиаторов воспаления в цереброспинальной жидкости позволяет установить их роль в патогенезе заболевания и расширить возможности патогенетической терапии, а также использовать результаты исследований в клинической практике для дифференциальной диагностики нейроинфекций.

Простота определения прокальцитонина, его биохимические и физиологические свойства и некоторые преимущества перед другими показателями воспаления делают прокальцитонин перспективным маркером для рутинного использования в отделениях интенсивной терапии и дифференциальной диагностики острого бактериального и вирусного менингитов, позволяя избежать ненужного лечения антибиотиками при вирусной этиологии заболевания $[10,11]$. Отечественных работ по определению уровня прокальцитонина и его диагностической значимости в цереброспинальной жидкости при менингитах у детей не проводилось, однако в литературе есть указание на исследование прокальцитонина в цереброспинальной жидкости у взрослых при бактериальном гнойном менингите $[12,13]$.

Цель исследования - установить значимость определения прокальцитонина в алгоритме дифференциальной диагностики менингитов разного генеза у детей для совершенствования тактики ведения пациентов в ранние сроки заболевания.

\section{Материал и методы}

В исследование были включены 88 пациентов в возрасте от 3 месяцев до 14 лет, госпитализированных в инфекционную клиническую больницу № 2 г. Москвы в период с 2013 по 2014 г. с направляющим диагнозом менингита. Среди них 13 (14,8\%) детей были в возрасте до 1 года, 38 (43,2\%) - от года до 5 лет и 37 (42\%) старше 5 лет.

В качестве дифференциальных критериев бактериального, вирусного менингитов и синдрома менингизма оценивались следующие параметры: уровень прокальцитонина в крови и цереброспинальной жидкости, а также плеоцитоз, клеточный состав, уровень глюкозы и белка по результатам общеклинического, биохимического исследования цереброспинальной жидкости. Всем пациентам была выполнена люмбальная пункция по стандартной методике в положении лежа на боку.

Определение концентрации прокальцитонина в цереброспинальной жидкости и сыворотке крови проводили на приборе Immunomat TWIN system твердофазным методом иммуноферментного анализа, основанного на принципе «сэндвича», с использованием тест-системы производства $3 \mathrm{AO}$ «Вектор-Бест» (г. Новосибирск, Россия) с порогом чувствительности 0,04 нг/мл. Специфическими реагентами набора были моноклональные антитела к прокальцитонину, сорбированные на поверхности лунок разборного полистирольного планшета; поликлональные антитела к прокальцитонину человека с биотином. В лунки планшета вносили по 20 мкл калибровочных образцов, контрольных образцов и анализируемые образцы сыворотки крови и ликвора, после чего планшет заклеивали пленкой и инкубировали в течение 60 минут на шейкере при температуре $37^{\circ} \mathrm{C}$. Аналитический цикл состоял из последовательных инкубаций с разными конъюгатами на шейкере (поликлональные антитела к прокальцитонину, стрептавидин-пероксидаза хрена, тетраметилбензидин и стоп-реагент) в течение 30 минут при температуре $37{ }^{\circ} \mathrm{C}$ и интенсивности перемешивания 700 об/мин, пятикратных промываний. Через 2-3 минуты после остановки реакции измерялась оптическая плотность с помощью фотометра для микропланшетов. Интенсивность желтого окрашивания была пропорциональна концентрации прокальцитонина в анализируемом образце. После измерения оптической плотности раствора в лунках на основании калибровочного графика рассчитывалась точная количественная концентрация прокальцитонина в исследуемых образцах. По данным литературы, у 80-90\% здоровых людей концентрация прокальцитонина в сыворотке крови составляет менее 0,05 нг/мл, у остальных не выше 0,1 нг/мл. Норма концентрации прокальцитонина в цереброспинальной жидкости была определена нами на основании исследования контрольной группы (пациенты без изменений в цереброспинальной жидкости). Критериями диагностики бактериального менингита служили положительная культура 


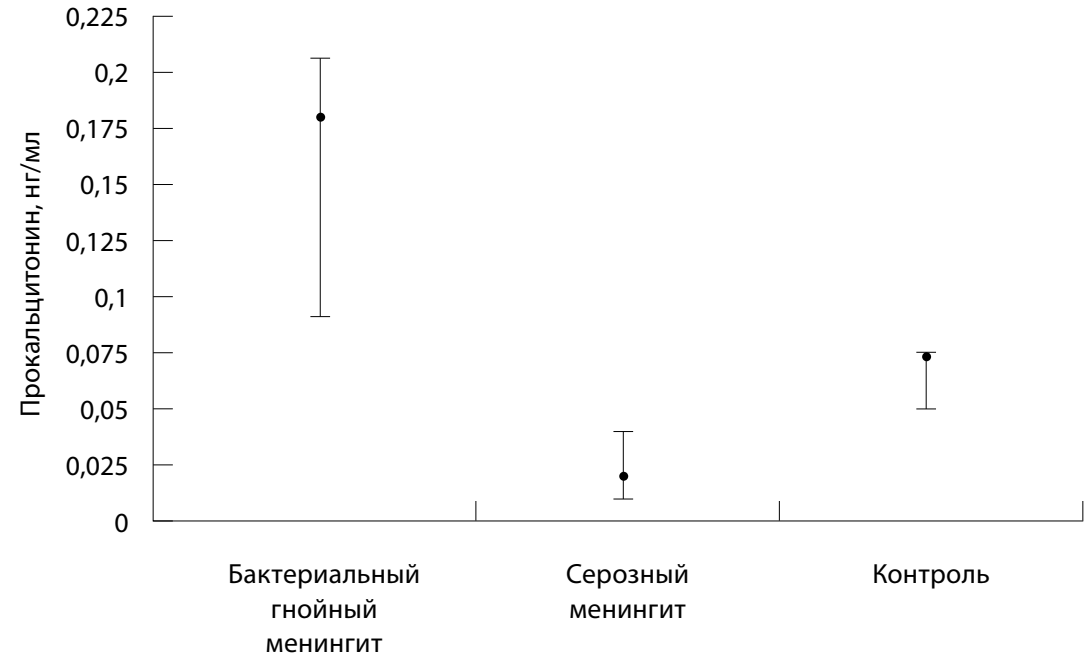

Рис. 1. Уровень прокальцитонина в цереброспинальной жидкости у пациентов с бактериальным, серозным менингитом и синдромом менингизма

цереброспинальной жидкости и/или наличие трехзначного плеоцитоза с преобладанием полиморфноядерных лейкоцитов, снижение уровня глюкозы и повышение уровня белка более 0,5 г/л.

Полученные данные были проанализированы с использованием методов описательной статистики, критерия $\chi^{2}$. Уровень $\mathrm{p}<0,05$ считался статистически значимым.

\section{Результаты}

У $40(45,4 \%)$ детей был диагностирован острый бактериальный менингит (1-я группа), у 24 (27,3\%) - вирусный менингит (2-я группа) и у $24(27,3 \%)$ - синдром менингизма на фоне других инфекционных заболеваний, протекающих без вовлечения в процесс мягких мозговых оболочек (группа контроля).

На момент поступления в стационар менингеальный синдром присутствовал у 97\% пациентов из 1-й группы, 72\% - из 2-й и у 63\% - из группы контроля. Продолжительность менингеального синдрома была максимальной в 1-й группе - более 4 дней у 69\% больных $(\mathrm{p}<0,05)$. Такое характерное клиническое проявление нейроинфекции, как рвота, отмечено у пациентов всех групп, которые между собой по этому признаку достоверно не различались ( $>>0,05)$. Однако при анализе частоты этого симптома оказалось, что в 1-й группе рвота более 3 раз в сутки регистрировалась чаще, чем в группе контроля и у пациентов с серозным менингитом $(\mathrm{p}<0,05)$. Лихорадка с одинаковой частотой и продолжительностью отмечалась во всех группах, но высота ее была значимо менее выражена у детей 2-й группы. Головная боль заболевания присутствовала с одинаковой частотой во всех наблюдениях, в то же время ее отсутствие в группе пациентов с серозным менингитом наблюдалось лишь в 4\%, что значительно отличалось от групп сравнения. Интенсивная и продолжительная головная боль регистрировалась одинаково часто во всех группах. Гиперестезия отмечена у 66,1\% пациентов с бактериальным гнойным менингитом, у 12 и 13,7\% - во 2-й и 3-й группах соответственно ( $<<0,05)$. Различные степени нарушения сознания выявлены только у пациентов 1-й группы. Таким образом, в характеристике клинической симптоматики не получено достоверных различий между проявлениями менингита в группах детей с бактериальным и вирусным менингитом. Это свидетельствует о том, что на основании только клинических симптомов определение характера воспаления не представляется возможным.

Исследование уровня прокальцитонина в крови при поступлении показало: наиболее высоким он был у пациентов 1-й группы $9,8(2,05 ; 13,19)$ нг/мл против $0,1(0,06 ; 0,14)$ нг/мл во 2 -й группе и $0,29(0,13 ; 1,5)$ нг/мл в группе контроля $(\mathrm{p}<0,05)$. Содержание прокальцитонина в цереброспинальной жидкости у пациентов с бактериальным гнойным менингитом - 0,14 (0,0; 0,34) нг/мл - также достоверно отличалось от группы больных с серозным менингитом - 0,02 $(0,01 ; 0,076$ нг/мл) и контрольной группы - 0,07 $(0,06 ; 0,07$ нг/мл, $\mathrm{p}=0,0000001$ и $\mathrm{p}=0,006)$ (рис. 1$)$. Обращает на себя внимание, что в группе пациентов с серозным менингитом средние значения

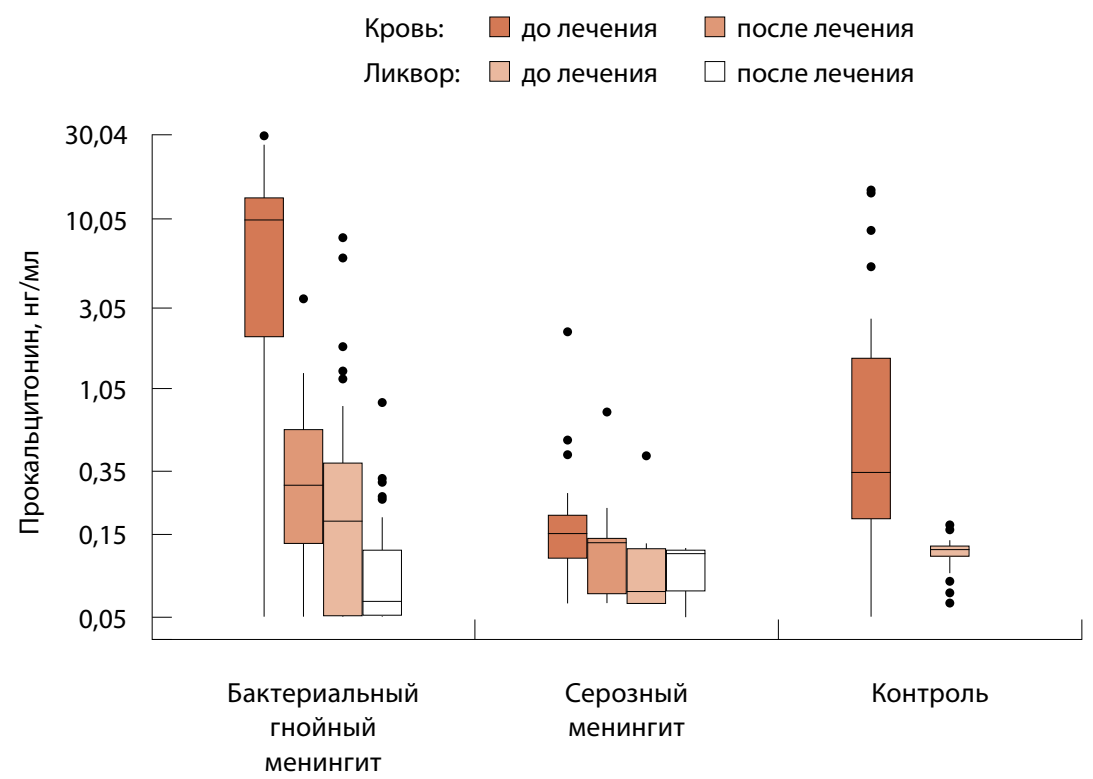

Рис. 2. Содержание прокальцитонина в крови и цереброспинальной жидкости в динамике 

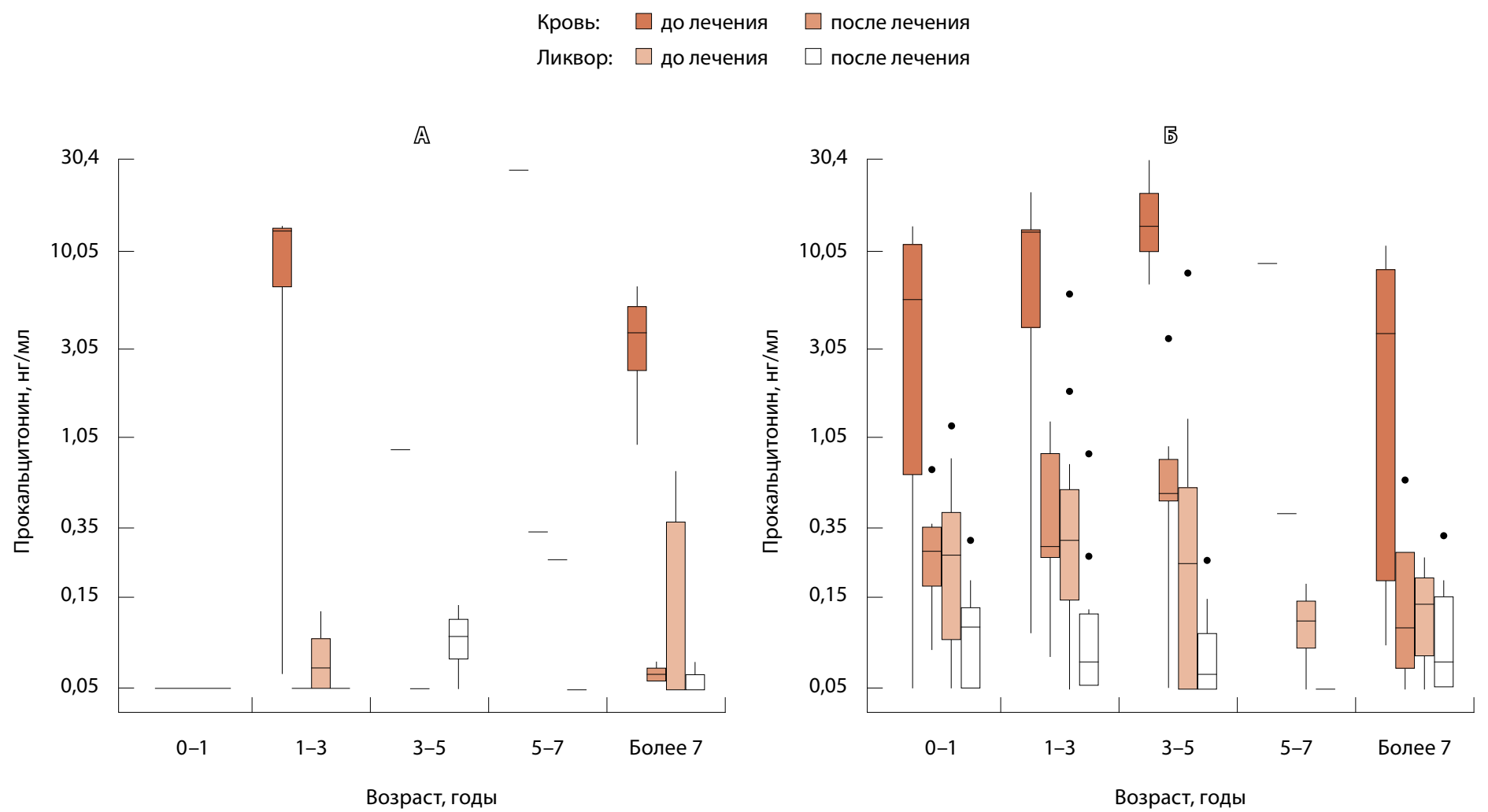

Рис. 3. Содержание прокальцитонина в крови и цереброспинальной жидкости у больных с бактериальным гнойным менингитом в зависимости от возраста и тяжести заболевания: А - средняя тяжесть, $\mathbf{5}$ - тяжелое течение

прокальцитонина в крови и цереброспинальной жидкости были ниже, чем в группе контроля (рис. 2).

При анализе уровня прокальцитонина в крови и цереброспинальной жидкости у больных с бактериальным гнойным менингитом в зависимости от тяжести заболевания и возраста статистически значимых различий выявлено не было (рис. 3). Уровень прокальцитонина коррелировал при этом с характером воспалительных изменений в ликворе и крови. Учитывая научно-практическую значимость исследования прокальцитонина в группе пациентов с бактериальным гнойным менингитом, мы проанализировали его уровень в зависимости от времени введения антибактериального препарата и глюкокортикоидных гормонов на догоспитальном этапе. Из данных рис. 4 видно, что введение глюкокортикостероидов не оказывает никакого влияния на уровень прокальцитонина в крови и сыворотке крови пациентов с бактериальным и серозным менингитом и детей из группы контроля. Повышенный уровень прокальцитонина в крови и цереброспинальной жидкости является информативным в остром периоде бактериального

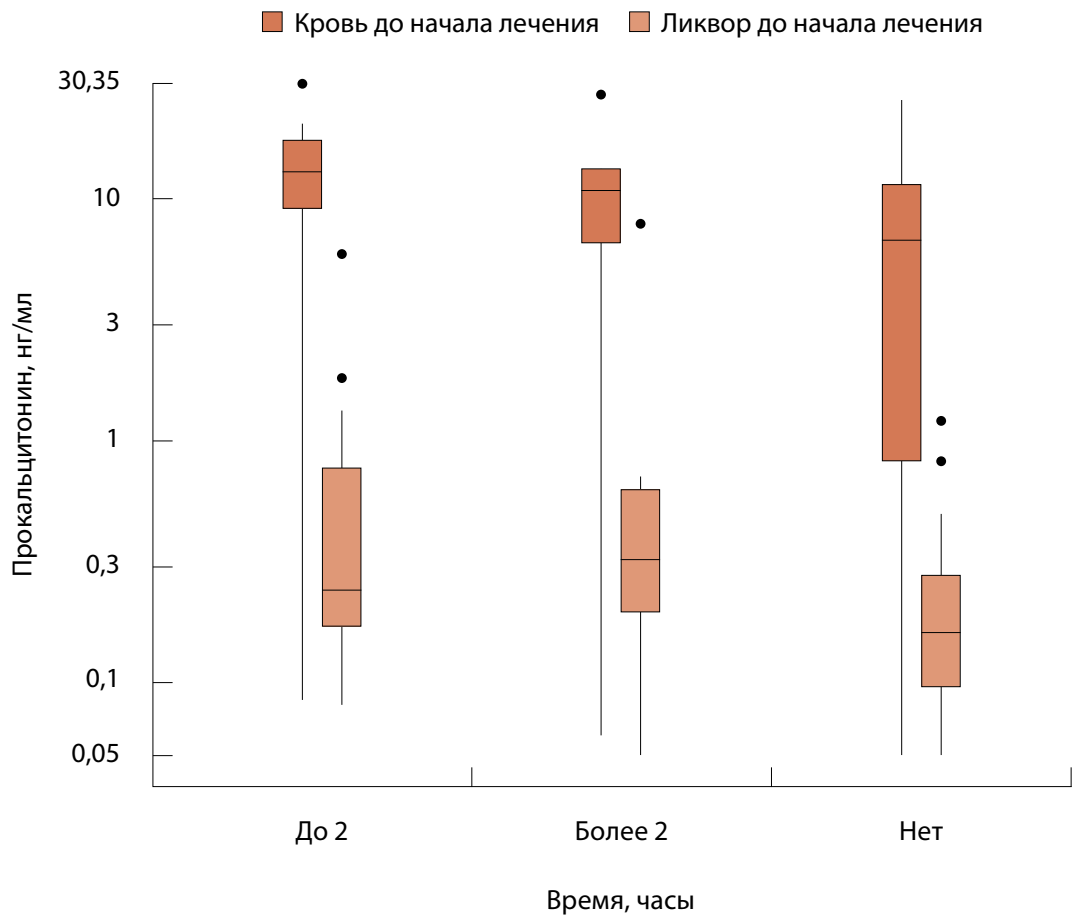

Рис. 4. Зависимость уровня прокальцитонина в крови и цереброспинальной жидкости от времени введения антибактериального препарата и глюкокортикостероида 
гнойного менингита и сохраняет свою диагностическую значимость независимо от проводимой на догоспитальном этапе терапии.

\section{Заключение}

В настоящее время нет точных клинических или лабораторных методов, позволяющих дифференцированно подходить к диагнозу острого бактериального или вирусного менингита быстро и однозначно. В нашем исследовании мы предприняли попытку оценить диагностическое и прогностическое значение прокальцитонина в крови и цереброспинальной жидкости у детей с менингитом. После проведения дополнительных обследований (включая серологический, бактериологический методы диагностики и полимеразную цепную реакцию) у 45,4\% установлен диагноз бактериального менингита, у 27,3\% серозного менингита и у 27,3\% детей отсутствовали воспалительные изменения в цереброспинальной жидкости (группа контроля). В процессе анализа не были выявлены статистически значимые различия в частоте и длительности основных клинических симптомов менингита (частота рвоты, наличие гиперестезии, выраженность лихорадки и головной боли), что до исследования ликвора не позволяло убедительно говорить о характере воспалительного процесса в цереброспинальной жидкости.
При исследовании уровня прокальцитонина в крови и цереброспинальной жидкости были получены статистически значимые различия между высокими показателями этого биомаркера в 1-й группе пациентов и 2-й и 3-й группах, что согласуется с данными аналогичных исследований, проведенных у взрослых пациентов с менингитом. Однако L. Кера и соавт. при обследовании 17 взрослых пациентов с бактериальным гнойным менингитом и 16 пациентов с вирусным менингитом получили более низкую диагностическую ценность определения прокальцитонина в цереброспинальной жидкости по сравнению с кровью. В этом исследовании уровень чувствительности тест-системы для определения уровня прокальцитонина был более 0,5 нг/мл [14], тогда как в нашей работе порог чувствительности метода составил 0,04 нг/мл.

Таким образом, исследование ликвора на содержание прокальцитонина в цереброспинальной жидкости обладает высоким диагностическим потенциалом для ранней дифференциальной диагностики бактериальных гнойных менингитов, оценки активности процесса, прогноза течения и исхода заболевания, что позволяет рекомендовать этот метод для включения в алгоритм обследования детей с нейроинфекциями. (\$)

\section{Литература}

1. Скрипченко НВ, Куликова КА. Современные патофизиологические аспекты бактериальных менингоэнцефалитов. Инфекционные болезни. 2014;12(2):76-82.

2. Алексеева ЛА, Скрипченко НВ, Бессонова ТВ. Диагностическое значение белков острой фазы в цереброспинальной жидкости детей с нейроинфекционными заболеваниями. Журнал инфектологии. 2010;2(2):28-34.

3. Хохлова ЗА, Лыкова ОФ, Конышева ТВ, Захарова ЕВ. Исследование содержания альбумина и альфа-2-макроглобулина в спинномозговой жидкости для оценки проницаемости гематоэнцефалического барьера при менингите. Бюллетень сибирской медицины. 2008;7 Приложение 1:88-91.

4. Молочный ВП, Макарова ТЕ, Головкова НФ, Обухова ГГ. Нейроспецифическая енолаза иглиофибриллярный кислый протеин крови и цереброспинальной жидкости как маркер повреждения ткани мозга при бактериальных гнойных менингитах у детей. Дальневосточный медицинский журнал. 2012;(2): 48-51.

5. Мазаева ЕМ, Алексеева ЛА, Скрипченко НВ, Бессонова ТВ. Клинико-ликворологические различия при серозных и гнойных менингитах у детей разного возраста. Детские инфекции. 2014;13(1):61-4.

6. Вельков ВВ. Прокальцитонин в диагностике критических состояний. Лабораторная медицина. 2009;(10):49-54.

7. Лыскина ГА, Дронов ИА, Тугаринова ГВ, Фоменко ТМ. Определение уровня прокальцитонина крови в педиатрической практике. Педиатрия. 2006;(4):32-44.

8. Choi SH, Choi SH. Predictive performance of serum procalcitonin for the diagnosis of bacterial meningitis after neurosurgery. Infect Chemother. 2013;45(3):308-14. doi: 10.3947/ ic.2013.45.3.308.

9. Данилов ДЕ, Карпов ИА, Титов ЛП. Провоспалительные цитокины и фактор некроза опухолей при гнойных менингитах. Белорусский медицинский журнал. 2003;(3):61-5.

10. Tunkle A, Beek O, Michael SW. Acute Meningitis. In: Mandell G, Bennett J, Dolin R, editors. Principles and Practice of Infectious Disease. $7^{\text {th }}$ ed. Philadelphia: Churchill Livingstone Elsevier; 2010. p. 1189-230.

11. Roos KL, Tyler KL. Meningitis, encephalitis, brain abscess and empyema. Chapter 376. In:
Kasper DL, Fauci AS, Longo DL, Braunwald E, Hauser SL, Jameson JL, editors. Harrison's principles of internal medicine. $17^{\text {th }}$ ed. USA: The McGraw-Hill; 2008. p. 2621-41.

12. Маттэу ДК, Нтэни Г, Контогиорги М, Поулякоу Г, Армаганидис А, Димопоулос Г. Использование уровня прокальцитонина при антибактериальной терапии больных, находящихся в критическом состоянии: систематический обзор и метаанализ Европейского общества интенсивной терапии. Инфекционные болезни: новости, мнения, обучение. 2013;(1):66-76.

13. Makoo ZB, Soltani HR, Hasani A, Makoo RB, Mashrabi $O$. Diagnostic value of serum and serum and cerebrospinal fluid procalcitonin in differentiation bacterial from aseptic meningitis. Am J Infect Dis. 2010;6(4):93-7.

14. Kepa L, Oczko-Grzesik B, Błedowski D. Procalcitonin (PCT) concentration in cerebrospinal fluid and plasma of patients with purulent and lymphocytic meningoencephalitis - own observations. Przegl Epidemiol. 2005;59(3):703-9. 


\section{References}

1.Skripchenko NV, Kulikova KA. Sovremennye patofiziologicheskie aspekty bakterial'nykh meningoentsefalitov [Modern patophisiological aspects of the bacterial meningoencephalitis]. Infektsionnye bolezni. 2014;12(2):76-82 (in Russian).

2. Alekseeva LA, Skripchenko NV, Bessonova TV. Diagnosticheskoe znachenie belkov ostroy fazy $v$ tserebrospinal'noy zhidkosti detey $s$ neyroinfektsionnymi zabolevaniyami [Diagnostic value of acute phase proteins in cerebrospinal fluid in children with neuroinfections]. Zhurnal infektologii. 2010;2(2):28-34 (in Russian).

3. Khokhlova ZA, Lykova OF, Konysheva TV, Zakharova EV. Issledovanie soderzhaniya al'bumina i al'fa-2-makroglobulina v spinnomozgovoy zhidkosti dlya otsenki pronitsaemosti gematoentsefalicheskogo bar'era pri meningite [The study of albumin and a2-macroglobulin levels in cerebrospinal fluid of patients with meningitis to evaluate blood brain barrier permeability]. Byulleten' sibirskoy meditsiny [Bulletin of Siberian Medicine]. 2008; 7 Suppl 1:88-91 (in Russian).

4. Molochnyy VP, Makarova TE, Golovkova NF, Obukhova GG. Neyrospetsificheskaya enolaza i gliofibrillyarnyy kislyy protein krovi i tserebrospinal'noy zhidkosti kak marker povrezhdeniya tkani mozga pri bakterial'nykh gnoynykh meningitakh $u$ detey [Neurospecific enolase and gliofiblar acid protein of blood and cerebrospinal fluid as a marker of cerebral tissue damage in bacterial purulent meningitis in children]. Dal'nevostochnyy meditsinskiy zhurnal. 2012;(2):48-51 (in Russian).

5. Mazaeva EM, Alekseeva LA, Skripchenko NV, Bessonova TV. Kliniko-likvorologicheskie razlichiya pri seroznykh i gnoynykh meningitakh u detey raznogo vozrasta [Clinical and liquor differences in cases of serous and purulent meningitis in children of different age]. Detskie infektsii. 2014;13(1):61-4 (in Russian).

6. Vel'kov VV. Prokal'tsitonin v diagnostike kriticheskikh sostoyaniy [Procalcitonin in the diagnostics of the critically ill]. Laboratornaya meditsina. 2009;(10):49-54 (in Russian).

7. Lyskina GA, Dronov IA, Tugarinova GV. Opredelenie urovnya prokal'tsitonina krovi $v$ pediatricheskoy praktike [Determination of procalcitonin level in pediatrics]. Pediatriya. 2006;85(4):32-46 (in Russian).

8. Choi SH, Choi SH. Predictive performance of serum procalcitonin for the diagnosis of bacterial meningitis after neurosurgery. Infect Chemother. 2013:45(3):308-14. doi: 10.3947/ ic.2013.45.3.308.

9. Danilov DE, Karpov IA, Titov LP. Provospalitel'nye tsitokiny i factor nekroza opukholey pri gnoynykh meningitakh [Antiinflammatory cytokines and tumor necrosis factor in sup- purative meningitis]. Belorusskiy meditsinskiy zhurnal. 2003;(3):61-5 (in Russian).

10. Tunkle A, Beek O, Michael SW. Acute Meningitis. In: Mandell G, Bennett J, Dolin R, editors. Principles and Practice of Infectious Disease. $7^{\text {th }}$ ed. Philadelphia: Churchill Livingstone - Elsevier; 2010. p. 1189-230.

11. Roos KL, Tyler KL. Meningitis, encephalitis, brain abscess and empyema. Chapter 376. In: Kasper DL, Fauci AS, Longo DL, Braunwald E, Hauser SL, Jameson JL, editors. Harrison's principles of internal medicine. $17^{\text {th }}$ ed. USA: The McGraw-Hill; 2008. p. 2621-41.

12. Matthaiou DK, Ntani G, Kontogiorgi M, Poulakou G, Armaganidis A, Dimopoulos G. An ESICM systematic review and meta-analysis of procalcitonin-guided antibiotic therapy algorithms in adult critically ill patients. Infektsionnye bolezni: novosti, mneniya, obuchenie. 2013;(1):66-76 (in Russian).

13. Makoo ZB, Soltani HR, Hasani A, Makoo RB, Mashrabi $O$. Diagnostic value of serum and serum and cerebrospinal fluid procalcitonin in differentiation bacterial from aseptic meningitis. Am J Infect Dis. 2010;6(4):93-7.

14. Kepa L, Oczko-Grzesik B, Błedowski D. Procalcitonin (PCT) concentration in cerebrospinal fluid and plasma of patients with purulent and lymphocytic meningoencephalitis - own observations. Przegl Epidemiol. 2005;59(3): 703-9.

\title{
Measurement of procalcitonin in the cerebrospinal fluid for differential diagnostics in children with meningitis
}

\author{
Mazankova L.N. ${ }^{1}$ Guseva G.D.1,2 • Moiseenkova D.A. ${ }^{1,3}$ • \\ Molotilova T.N. ${ }^{3}$ • Aleshina N.I. ${ }^{3}$
}

Background: High production of pro-inflammatory cytokines associated with procalcitonin synthesis and its increased blood levels play an important role in the pathophysiology of systemic inflammation in generalized bacterial infections. Aim: To assess diagnostic value of procalcitonin measurement as a marker of bacterial inflammation in cerebrospinal fluid for differential diagnostics of bacterial and viral meningitis. Materials and methods: Procalcitonin levels in blood and cerebrospinal fluid were measured by immunoenzyme analysis in 88 children aged from 3 months to 14 years who had been admitted to the hospital. Forty five percent $(45.4 \%)$ of them had acute bacterial meningitis, $27.3 \%$, viral meningitis and $27.3 \%$ had the meningitis-like syndrome (control group). Results: There was a high procalcitonin level in cerebrospinal fluid in patients with bacterial purulent meningitis $(0,14[0.0 ; 0.34] \mathrm{ng} / \mathrm{mL}(\mathrm{p}<0.006)$, with the normal range in the control group of 0.07 [0.0;0.07] $\mathrm{ng} / \mathrm{mL}$. This parameter correlated with blood procalcitonin level $(9.8$ [2.05; 13.19] $\mathrm{ng} / \mathrm{mL}$ ) and severity of meningitis. In patients with viral meningitis, the procalcitonin levels were below the normal range $(0.02[0.01 ; 0.07] \mathrm{ng} / \mathrm{mL})$. Conclusion: Measurement of procalcitonin levels in cerebrospinal fluid could be recommended for inclusion into the differential diagnostic algorithm of meningitis of various etiologies in children.

Key words: children, meningitis, procalcitonin, blood, cerebrospinal fluid, algorithm, differential diagnostics

doi: 10.18786/2072-0505-2015-42-96-102
Mazankova Lyudmila N. - MD, PhD, Professor, Head of Chair of Pediatric Infectious Diseases $\triangle$ 2/1 Barrikadnaya ul., Moscow, 125993, Russian Federation. Tel.: +7 (903) 6289242

E-mail: mazankova@list.ru

Guseva Galina D. - PhD, Assistant, Chair of Pediatric Infectious Diseases'; Specialist in Infectious Disease, Department of Infectious Control ${ }^{2}$

Moiseenkova Dar'ya A. - Postgraduate Student Chair of Pediatric Infectious Diseases'; Pediatrist Pediatric Box Department ${ }^{3}$

Molotilova Tat'yana N. - Head of Express Laboratory ${ }^{3}$

Aleshina Nina I. - Specialist in Laboratory Diagnostics, Express Laboratory ${ }^{3}$
Russian Medical Academy of Postgraduate Education; 2/1 Barrikadnaya ul., Moscow, 125993, Russian Federation

${ }^{2}$ Federal Research Center of Pediatric Hematology Oncology and Immunology named after Dmitry Rogachev; 1 Samory Mashela ul., GSP-7, Moscow, 117997, Russian Federation

${ }^{3}$ Infectious Diseases Clinical Hospital No 2 15 The $8^{\text {th }}$ Sokolinoy gory ul., Moscow, 105275 , Russian Federation 